\title{
НЕКОТОРЫЕ АСПЕКТЫ СОВЕРШЕНСТВОВАНИЯ РОССИЙСКОГО ЗАКОНОДАТЕЛЬСТВА О КУРОРТАХ НА СОВРЕМЕННОМ ЭТАПЕ'
}

В статье рассматриваются некоторые тенденции развития законопроектной работы на пути совершенствования российского законодательства о курортах. За основу взят проект №555658-6 Федерального закона «О внесении изменений в Земельный кодекс Российской Федерации, Градостроительный кодекс Российской Федерации и отдельные законодательные акты Российской Федерации», который рассматривается на сегодняшний день в Государственной Думе. Анализ этого законопроекта показал, что в последнее время разработчики изменений в российское законодательство о курортах стремятся к его «деэкологизации», то есть к смягчению нормативных запретов, установленных с целью сохранения и рационального использования природных лечебных ресурсов. В законопроекте выявлены некоторые «болевые точки», связанные с пред- полагаемой отменой существующей классификации российских курортов, с изменением порядка управления ими и правового режима их отдельных зон с особыми условиями использования, с грядущей «амнистией» незаконных строений на курортах. Сделан вывод о том, что такие нововведения скажутся самым негативным образом на состоянии курортов. Выявлены «лоббистские тенденции» в процессе изменения курортного законодательства с целью беспрепятственной реализации некоторых бизнес-интересов в строительной и иных сферах. Обусловливается нормативная модель оптимального соотношения таких интересов с сохранением курортов как одного из важнейших общественных благ на современном этапе.

Ключевые слова: курорты, законодательство, лоббизм, законопроект.

\section{E. S. Navasardova, R. V. Nutrikhin}

\section{SOME ASPECTS OF IMPROVEMENT OF THE RUSSIAN LEGISLATION ON RESORTS AT THE PRESENT STAGE}

The article studies some tendencies of development of lawmaking work on the way of improvement of the Russian legislation on resorts. The draft No. 555658-6 of the Federal law "On Modification of the Land Code of the Russian Federation, the Town-planning Code of the Russian Federation and Separate Acts of the Russian Federation" which is considered in the State Duma today is taken as the basis. The analysis of this bill showed that nowadays the developers of changes in the Russian legislation on resorts tend to its "deecologization", that is to mitigation of the standard bans established for the purpose of preservation and rational use of medical natural resources. The bill reveals some "painful points" connected with alleged cancellation of the existing classification of the Russian resorts, change of management order and a legal regime of their separate zones with special conditions of use, future "amnesty" of illegal structures in resorts. The conclusion is drawn that such innovations will affect the quality negatively. "Lobbist tendencies" in the course of change of the resort legislation for the purpose of free realization of some business interests in construction and other spheres are revealed. The legal model of an optimum ratio of such interests with preservation of resorts as one of the major public benefits at the present stage is stated.

Key words: resorts, legislation, lobbyism, bill.
В последние годы в России ведется большая законопроектная и законотворческая работа, направленная на совершенствование правового режима отечественных курортов [1, с. 66].

\footnotetext{
1 Статья подготовлена в рамках выполнения государственного контракта от 31 мая 2018 г. № 108/ОК на оказание услуг по проведению экспертно-аналитических исследований по теме: «Подходы к совершенствованию правового регулирования охраны и использования лечебно-оздоровительных местностей и курортов», заключенного между Аппаратом Государственной Думы Федерального Собрания Российской Федерации и ФГБОУ ВО «Московский государственный юридический университет имени О. Е. Кутафина (МГЮА)».
} 
Иными словами, идет напряженный поиск наиболее оптимальных юридических средств и нормативных алгоритмов, которые способствовали бы сохранению природоресурсного потенциала российских курортов, помогли бы преодолеть их начавшуюся стагнацию и задать вектор их дальнейшего развития. Наряду с неизбежными трудностями теоретико-правового и юридико-технического характера разработка нового законодательства в данной сфере наталкивается на серьезные лоббистские преграды. Вопрос о правовом режиме курортов оказывается в фокусе самых разных, прежде всего, экономических интересов. Поскольку лейтмотивом правовых норм, направленных на охрану курортов и рациональное использование их ресурсов, являются всевозможные запреты и ограничения, то на их содержание пытаются влиять представители строительного и иного бизнеса, муниципальные власти и другие субъекты, заинтересованные в беспрепятственном осуществлении хозяйственной деятельности на территории курортов, в предоставлении там земельных учатсков и прочих очевидных выгодах, которые соответствующее законодательство как раз призвано ограничивать с целью сохранения курортов для настоящего и будущих поколений [3, с. 109]. Борьба различных лоббистских влияний в законопроектной деятельности по столь важному вопросу представляет собой весьма интересный социальный феномен, изучение которого может способствовать глубокому пониманию социальных процессов, происходящих в данной сфере, и как результат - более эффективному совершенствованию законодательства о курортах.

Наиболее крупным и универсальным документом в этой связи является проект №555658-6 Федерального закона «О внесении изменений в Земельный кодекс Российской Федерации, Градостроительный кодекс Российской Федерации и отдельные законодательные акты Российской Федерации» (далее законопроект), внесенный в Государственную Думу Правительством РФ в середине 2014 года и рассмотренный на настоящий момент только в первом чтении. Важность данного проекта очевидна, поскольку в нем предпринята попытка восполнить пробелы и разрешить противоречия, возникшие за последние годы в законодательстве о лечебно-оздоровительных местностях и курортах. Однако актуальная на сегодняшний день редакция документа содержит ряд положений, которые могут привести не к улучшению, а к ухудшению ситуации в этой области общественных отношений.
Наиболее «революционным» нововведением законопроекта является отмена подразделения всех курортов страны на курорты федерального, регионального и местного значения. Между тем, эта ключевая классификация, присутствующая в ныне действующей редакции Федерального закона от 23.02.1995 г. №26-Ф3 «О природных лечебных ресурсах, лечебно-оздоровительных местностях и курортах», составляет основу его понятийного базиса. Данная классификация формирует всю систему российских курортов и во многом предопределяет особенности правового режима каждого из них. Предлагаемая законопроектом фрактическая нивелировка различных по своему значению курортов, которые в случае его принятия будут различаться между собой только по способу их создания и особенностям реализации в отношении них некоторых публичных полномочий, никоим образом не упорядочит сореру санаторно-курортного лечения в России, а лишь создаст весьма нежелательную неопределенность.

Опасность такого нововведения очевидна хотя бы потому, что существующий на сегодняшний день на фредеральном уровне весь массив соответствующих подзаконных актов принят в отношении курортов именно федерального значения (например, Постановление Правительства РФ от 07.12.1996 г. №1425 «Об утверждении Положения об округах санитарной и горно-санитарной охраны лечебно-оздоровительных местностей и курортов федерального значения» и т.д.). Если «курорты федерального значения» перестанут существовать как правовое понятие, то и вся указанная база подзаконных актов утратит в отношении них свою юридическую силу. То есть перестанут действовать установленные данными актами ограничения хозяйственной деятельности на важнейших по значению курортах, а также иные особенности их функционирования, что едва ли приведет к достижению каких-либо позитивных результатов. Когда еще будет разработан новый пакет соответствующих подзаконных актов - большой вопрос. А до этого времени правовой режим бывших «курортов федерального значения», по сути, лишится обширного, наработанного годами детального подзаконного регулирования, чего, на наш взгляд, допускать нельзя. Важно сохранить ныне существующее подразделение российских курортов на курорты федерального, регионального и местного значения в целях недопущения столь нежелательной неразберихи и дополнительной неопределенности. 
Кроме того, понятие «курорты федерального значения» предполагает наличие соответствующих расходных обязательств в федеральном бюджете на содержание и развитие наиболее значимых отечественных курортов. Некоторые представители экспертного сообщества видят в тенденции к отказу от выделения данной категории стремление сократить бюджетные расходы Российской Федерации в курортной сфрере и переложить их на плечи ее субъектов. Такая экономия бюджетных средств не может положительно сказаться на состоянии курортов, а точнее - только ускорит их деградацию.

Вызывает тревогу у экспертов и попытка исключить из Федерального закона от 23.02.1995 г. №26-Ф3 «О природных лечебных ресурсах, лечебно-оздоровительных местностях и курортах» целые правовые институты. Такие, например, как государственная поддержка развития курортов в Российской Федерации (ст. 13 в действующей редакции). Сейчас в п. 1 ст. 13 установлено, что поддержка развития курортов федерального значения является расходным обязательством Российской Федерации. Однако рассматриваемый законопроект эту норму предлагает исключить. Конечно, существующая в стране система финансирования курортного дела еще очень далека от совершенства [4, с. 168]. Однако полное упразднение в федеральном законодательстве института государственной поддержки развития курортов едва ли будет способствовать упорядочению соответствующих отношений и достижению социально-значимых целей их правового регулирования.

В законопроекте наблюдается очевидная тенденция к изменению существующего порядка управления курортами в сторону передачи некоторых важных полномочий на более низкий уровень. В частности, установление и изменение границ округа горно-санитарной охраны курортов федерального значения в настоящее время осуществляется Правительством РФ (п. 2 ст. 16 Ф3 «О природных лечебных ресурсах, лечебно-оздоровительных местностях и курортах»). Разработчики законопроекта предлагают наделить полномочиями по принятию соответствующих решений фредеральный орган исполнительной власти, уполномоченный на это Правительством. Из ст. 96 Земельного кодекса РФ законопроектом изымается положение о том, что границы и режим округов санитарной (горно-санитарной) охраны курортов, имеющих федеральное значение, устанавливаются Правительством РФ. В этом усматривается стремление упростить суще- ствующий порядок установления и изменения указанных границ в интересах хозяйствующих субъектов и застройщиков, но никак не в целях охраны природно-лечебных ресурсов, на страже которых должно стоять государство в лице своего высшего органа исполнительной власти - Правительства РФ. По нашему мнению, в федеральном законодательстве должны быть сохранены нормы о том, что границы округов санитарной (горно-санитарной) охраны для лечебно-оздоровительных местностей и курортов федерального значения утверждаются Правительством. Только так может быть обеспечено принятие соответствующих решений на достаточно высоком государственном уровне. С этой точки зрения передача указанных полномочий от Правительства РФ одному из федеральных министерств представляется крайне нежелательной.

Значительным недостатком законопроекта является установление разного порядка для признания просто курортов, расположенных в границах двух и более субъектов Российской Федерации, и так называемых «курортных регионов». В первом случае предполагается, что вполне достаточно решения Правительства РФ, тогда как во втором случае будет необходимо принятие специального федерального закона. Однако из текста законопроекта не ясна разница между понятиями «курортный регион» и «курорт, расположенный в границах двух и более субъектов РФ». Из предлагаемой редакции абз. 8 ст. 1 ФЗ «О природных лечебных ресурсах, лечебно-оздоровительных местностях и курортах» следует, что это вроде бы одно и то же. Однако законопроект предлагает установить для них совершенно разный порядок признания - принятием специального федерального закона для курортных регионов и просто решением Правительства РФ для курортов, охватывающих территорию более одного субъекта Федерации. Не вполне очевидна и никак не обоснована необходимость принятия отдельного федерального закона для каждого могущего возникнуть в России курортного региона. В этой части законопроекта необходимо достижение большей последовательности, а также терминологической ясности и определенности.

Довольно тревожным нововведением, присутствующим в интересующем нас законопроекте, является допущение возможности: 1) признания природных лечебных ресурсов курортов истощенными и утратившими лечебные свойства; 2) прекращения существования на курортах округов горно-санитарной охраны; 
3) признания территории утратившей статус лечебно-оздоровительной местности или курорта (см. предлагаемую редакцию абз. 4-6, 8 ст. 4; п. 4 ст. 152; п. 2-3 ст. 16; п. 11 ст. 161 Ф3 «О природных лечебных ресурсах, лечебно-оздоровительных местностях и курортах» и др.). Насколько нам известно, ни один из курортов, признанных в таковом качестве как в Российской империи, так и в СССР, а также установленные в их пределах округа горно-санитарной охраны до сего дня не упразднялись [2, с. 48], и каких-либо объективных предпосылок для столь нежелательного развития событий в будущем тоже не предвидится.

Федеральное законодательство должно быть нацелено на сохранение курортов и их природных ресурсов, а также на поддержание установленных для этой цели округов горно-санитарной охраны, а никак не на прекращение их существования. Само упоминание о такой вероятности представляется крайне нежелательным, не говоря уже об открывающихся в связи с этим возможностях для самых чудовищных злоупотреблений. Ранее наше законодательство не допускало ликвидации целых курортов и установленных на них округов санитарной (горно-санитарной) охраны, и хочется надеяться, что этого не будет допущено и впредь.

Имеется немало вопросов к прописанному в законопроекте новому правовому режиму трех зон округа горно-санитарной охраны на курортах. В настоящее время осуществление хозяйственной деятельности в данных зонах регламентируется Ф3 «О природных лечебных ресурсах, лечебно-оздоровительных местностях и курортах» и принятым в соответствии с ним «Положением об округах санитарной и горно-санитарной охраны лечебно-оздоровительных местностей и курортов федерального значения», которое было утверждено Постановлением Правительства РФ от 07.12.1996 г. №1425.

Думается, что в процессе совершенствования данного правового института определяемый им режим хозяйственной деятельности в трех зонах округа горно-санитарной охраны должен быть по своим стандартам не ниже существующего. Точечное или повсеместное смягчение этого режима может привести к самым нежелательным последствиям, однако именно это и предлагается рассматриваемым законопроектом.

Сегодня в первой зоне на курортах федерального значения запрещается: проживание и все виды хозяйственной деятельности, за исключением работ, связанных с исследова- ниями и использованием природных лечебных ресурсов в лечебных и оздоровительных целях при условии применения экологически чистых и рациональных технологий. Однако законопроект допускает, например, размещение в первой зоне средств связи. Понятно, что такая деятельность не имеет никакого отношения к исключительно лечебно-оздоровительным целям создания этой зоны. Предлагаемая норма выглядит как средство устранения «экологических барьеров» на пути реализации интересов мобильных операторов и иных субъектов сферы услуг связи - явно не в целях сохранения курортов [5, с. 55].

На территории второй зоны округа горно-санитарной охраны курортов федерального значения в настоящий момент запрещается: размещение объектов и сооружений, не связанных непосредственно с созданием и развитием сореры курортного лечения и отдыха, а также проведение работ, загрязняющих окружающую среду, природные лечебные ресурсы и приводящих к их истощению. В рассматриваемом законопроекте столь категоричный запрет отсутствует. Там не допускается лишь строительство и размещение объектов, оказывающих особо негативное воздействие на окружающую среду. Такое смягчение режима второй зоны также представляется недопустимым. Законопроект не исключает строительства во второй зоне многоэтажных жилых домов, торговых центров и других зданий, не имеющих никакого отношения к санаторно-курортному лечению и рекреации, тогда как их возведение во второй зоне должно быть в обязательном порядке ограничено по вполне понятным причинам, как это и определено в действующем законодательстве. Если мы хотим сохранить курорты, то смягчать эту норму тоже нельзя.

Сейчас для третьей зоны на всех курортах федерального значения законодательством установлены ограничения на размещение промышленных и сельскохозяйственных организаций и сооружений, действует запрет на осуществление хозяйственной деятельности, сопровождающейся загрязнением окружающей среды, природных лечебных ресурсов и их истощением. Рассматриваемый законопроект никаких конкретных ограничений такого рода не предусматривает. В границах третьей зоны округа горно-санитарной охраны он допускает осуществление любой деятельности при соблюдении общих нормативов охраны окружающей среды. То есть никаких специальных запретов для третьей зоны в законопроекте нет. И совершенно уже неясно, в чем состоит 
особый режим этой зоны? Для чего она вообще создается? К чему сводится смысл ее существования?

Можно сделать вывод, что исследуемый законопроект допускает необоснованную либерализацию существующего правового режима трех зон округа санитарной (горно-санитарной) охраны курортов. Это может быть выгодно, прежде всего, застройщикам, но никак не отвечает интересам общества по сохранению природных лечебных ресурсов и охране окружающей среды на курортах. Понятно, что при существующем порядке возникает немало проблем, связанных с дисбалансом довольно строго режима трех зон и необходимостью развития урбанистской инфраструктуры. Однако решать эти проблемы нужно не всеохватным ослаблением действующих запретов, введенных с благой целью сохранения природоресурсного курортного потенциала, а путем разработки более сложных инструментов дифрференцированного правового регулирования.

Нельзя не отметить, что авторы законопроекта предприняли попытку «амнистировать» все нелегальные строения, возведенные в границах округов санитарной (горно-санитарной) охраны российских курортов вплоть до даты придания указанному проекту силы закона. Такая повальная «амнистия» построек, созданных на курортах с грубым нарушением действующего законодательства, едва ли чем-то оправдана. К этому вопросу необходимо подходить куда более взвешенно, как и к освобождению уже утвержденных проектов капитальных зданий от прохождения государственной экологической экспертизы, что также предлагается законопроектом.

Явные недостатки законопроектной работы в сфере совершенствования правового режима отечественных курортов накладываются на уже существующие пробелы в законодательстве. Так, например, в законопроекте предлагается норма, согласно которой границы лечебно-оздоровительных местностей и курортов должны описываться в системе координат, используемой при ведении Единого государственного реестра недвижимости (ЕГРН). Статья 10 Федерального закона от 13.07.2015 г. №218-Ф3 «О государственной регистрации недвижимости» действительно регулирует ведение в рамках ЕГРН реестра границ, куда вносятся сведения о границах различных территорий с особыми условиями использования. Однако ни границы курортов, ни границы зон их округов санитарной (горно-санитарной) ох- раны там даже не упоминаются. Для надежной фиксации названных границ рассматриваемым законопроектом стоило бы внести изменения в ст. 10 и другие нормы Ф3 «О государственной регистрации недвижимости», предусмотрев обязательную регистрацию границ лечебно-оздоровительных местностей и курортов, а также границ зон округов их санитарной (горно-санитарной) охраны в реестре границ ЕГРН.

Не относил к зоне округа санитарной (горно-санитарной) охраны к категории зоны с особыми условиями использования и Градостроительный кодекс РФ. Только в 2018 году внесены изменения в законодательство и, в частности, Земельный кодекс РФ в новой XIX главе к зонам с особыми условиями использования территорий допускает отнесение округа санитарной (горно-санитарной) охраны лечебно-оздоровительных местностей, курортов и природных лечебных ресурсов. Подчеркнем, что норма ст. 105 диспозитивная. Хотя уже в 106 статье, где говорится о том, что Правительство РФ утверждает положение в отношении каждого вида зон с особыми условиями использования территорий, делается исключение для зон с особыми условиями использования территорий, которые возникают в силу федерального закона, Округа санитарной (горно-санитарной) охраны не упоминаются, несмотря на то, что действующий Ф3 «О природных лечебных ресурсах, лечебно-оздоровительных местностях и курортах» создание таких зон предусматривает.

Это, конечно, далеко не все недостатки актуальных законопроектных инициатив, направленных на совершенствование правового режима курортов в России. Но уже и эти выявленные проблемы позволяют говорить об обозначившейся тенденции к «деэкологизации» курортного законодательства. Существующие в нем ограничения и запреты, очевидно, рассматриваются теперь как нежелательные «преграды» и «препоны» на пути осуществления хозяйственной деятельности и реализации всевозможных бизнес-интересов. При этом как-то забывается о том, что упраздняемые запреты и ограничения устанавливались вовсе не против бизнеса как такового, а в целях сохранения курортов как бесценного природоресурсного достояния, как неотъемлемого компонента национальной системы здравоохранения. Ведь даже при самом прагматичном подходе к регулированию данных отношений все же следует признать, что без сбережения здоровья всякий рост благосостояния общества лишается какого-либо рационального смысла. 


\section{Литература}

1. Бабич М. Е. Кавказские Минеральные Воды: на пути к новому регулированию // Экологический вестник России. 2018. №6. C. 66-69.

2. Белозерова Е. В. История формирования законодательства о курорте Кавказские Минеральные Воды // Общество и право. 2010. №1. С. 46-49.

3. Навасардова Э. С. К вопросу об управлении курортом «Кавказские Минеральные Воды» // Общество и право. 2012. №4. C. 107-111.

4. Навасардова Э. С., Нутрихин Р. В., Колесникова К. В. Состояние и тенденции развития эколого-курортного законодательства в Российской Федерации // Приоритетные направления развития экологического, земельного и аграрного права. Материалы Республиканского круглого стола, приуроченного к юбилею д-ра юрид. наук, проф. Т. И. Макаровой. Минск: Издательский центр БГУ, 2017. С. 168-171.

5. Нутрихин Р. В. Правовой режим ставропольских курортов федерального значения в свете проекта закона о Кавказских Минеральных Водах // НаукаПарк. 2017. №4. С. 54-56.

\section{References}

1. Babich M. E. Kavkazskie Mineral'nye Vody: na puti k novomu regulirovaniyu (Caucasus Mineralnye Vody region: on the way to new regulation) // Ehkologicheskij vestnik Rossii. 2018. No.6. P. 66-69. (In Russian).

2. Belozerova E. V. Istoriya formirovaniya zakonodatel'stva o kurorte Kavkazskie Mineral'nye Vody (History of formation of the legislation on the resort Caucasus Mineralnye Vody region) // Obshchestvo i pravo. 2010. No.1. P. 46-49. (In Russian).

3. Navasardova E. S. K voprosu ob upravlenii kurortom «Kavkazskie Mineral'nye Vody» (On management of the resort Caucasus Mineralnye Vody region) // Obshchestvo i pravo. 2012. No.4. P. 107-111. (In Russian).

4. Navasardova E. S., Nutrikhin R. V., Kolesnikova K. V. Sostoyanie i tendencii razvitiya ehkologo-kurortnogo zakonodatel'stva $\vee$ Rossijskoj Federacii (The state and tendencies of development of the ecology-resort legislation in the Russian Federation) // Prioritetnye napravleniya razvitiya ehkologicheskogo, zemel'nogo i agrarnogo prava. Materialy Respublikanskogo kruglogo stola, priurochennogo k yubileyu d-ra yurid. nauk, prof. T. I. Makarovoj. Minsk: Izdatel'skij centr BGU, 2017. P. 168-171. (In Russian).

5. Nutrikhin R. V. Pravovoj rezhim stavropol'skih kurortov federal'nogo znacheniya v svete proekta zakona o Kavkazskih Mineral'nyh Vodah (A legal regime of the Stavropol resorts of federal importance in the light of the bill on Caucasus Mineralnye Vody region) // NaukaPark. 2017. No.4. P. 54-56. (In Russian) 